\title{
Foveal Avascular Zone in Pseudoexfoliation Glaucoma Measured by Optical Coherence Tomography Angiography
}

tolga kocaturk ( $\nabla$ tolgakocaturk@gmail.com )

Adnan Menderes Universitesi

tolga kocaturk ( $\nabla$ tolgakocaturk@gmail.com )

Adnan Menderes Universitesi

Volkan Dayanir

Batıgöz Hospital

Research article

Keywords:

Posted Date: April 3rd, 2020

DOI: https://doi.org/10.21203/rs.2.9886/v2

License: (c) (i) This work is licensed under a Creative Commons Attribution 4.0 International License.

Read Full License 
The authors have withdrawn this preprint from Research Square 